\title{
Participación de las unidades de documentación televisivas en la creación del producto audiovisual en programas informativos
}

\author{
Jorge Caldera Serrano \\ $M^{\text {a }}$ Victoria Nuño Moral \\ Facultad de Biblioteconomía y Documentación \\ Universidad de Extremadura
}

\subsection{Resumen}

Se muestran las fases por las cuales pasa un acontecimiento informativo antes de ser considerado una noticia lo suficientemente relevante para ser emitida por la empresa televisiva. Destacan aquellas en las cuales se requiere el trabajo de los servicios de documentación. Se alude a las formas de trabajo informativo-documental que desarrollan la mayor parte de las cadenas televisivas. Dichas unidades documentales pueden ser de naturaleza visual, sonora y escrita. (Autor)

Palabras clave: Servicio de documentación. Elaboración de noticias. Documentación audiovisual. Servicios informativos. Televisión.

\subsection{Abstract}

The different phases that take place for an informative event to be considered relevant enough to be broadcasted by a television company are analysed. Those phases where the work of the documentation services is required are emphasized. The different kind of documentary tasks developed in the majority of the television networks are mentioned. Such documentary units can be of a visual, sound or written nature. (Author)

Keywords: Documentary service. News production. Audiovisual documents. Informative services. Television.

\section{Introducción.}

No vamos a descubrir la importancia de la televisión en nuestra sociedad. La nueva versión del antiguo "pan y circo" es la fórmula más usual de entretenimiento en la actualidad por su facilidad de acceso y lectura, además de lo atractivo que 
se nos muestra este formato tanto para adquirir información como para emplear nuestro tiempo de ocio de una forma absolutamente inactiva y teledirigida.

Lo que sí se pretende con el presente trabajo es demostrar la importancia que tiene el servicio de documentación de las empresas audiovisuales en la creación de un producto televisivo en programas informativos. Dicha importancia ha sido descubierta hace algún tiempo por los responsables de dichas empresas que intentan dotar de personal y recursos económicos a estos servicios que, con el tiempo, se muestran eficaces y rentables desde el punto de vista económico, factor prioritario en las empresas televisivas.

El proceso productivo progresa según fases claramente definidas: conceptualización, narración, valoración de noticiabilidad, selección, construcción discursiva (forma) y ubicación de la noticia (formato) (1). Estas diferentes etapas necesitan de la implicación de todos los profesionales del mundo de la comunicación con sus diversas especialidades para lograr así que el producto pueda estar completamente terminado y en perfecto estado de emisión.

\section{Fases del proceso de creación de la pieza audiovisual informativa}

Como señala Fraser Bond en su Introducción al periodismo:

El proceso de producción o rutinas productivas de la información periodística televisiva es, en buena mediada, una consecuencia de la escasez de tiempo y medios para la elaboración de la noticia, pero, sobre todo, es resultado del modelo productivo de las empresas y sus formas de organización, que priorizan la obtención de beneficio económico en un mercado competitivo, para lo cual resulta imprescindible la racionalización del trabajo, la reducción de costes con la consiguiente agilización del proceso.

Son muchos los pasos señalados en los diferentes manuales de periodismo para la creación de una noticia que se va a insertar en un Informativo. Por ello, se ha realizado un compendio de estas fases atendiendo a su facilidad de entendimiento por personas ajenas al ámbito periodístico en detrimento de la cientificidad y la profundización. En la primera parte de este trabajo se desarrolla de manera genérica el proceso de creación. Posteriormente, se desglosan las etapas y se señala en qué momentos entra en juego la documentación.

\subsection{Conceptualización}

La conceptualización es el proceso de interpretar correctamente un acontecimiento, un hecho o una realidad. Es decir, es necesario que aquello que acontece llame la atención periodística y que se considere suficientemente importante para profundizar en la interpretación del mismo. Esta noticia puede venir del contacto directo con la realidad por medio de la presencia física del periodista en el transcurso de esa acción o también puede producirse por la lectura y revisión de los 
miles de teletipos que llegan diariamente a las televisiones españolas tanto de difusión autonómica como estatal (2).

\subsection{Proceso de narración}

Es la segunda fase del laborioso proceso de creación del producto televisivo. Como todos sabemos, las noticias en televisión, al igual que ocurre en otros medios de comunicación, no son hechos aislados, sino que están en relación con su entorno y con informaciones que le han precedido y que, con seguridad, seguirán produciéndose en días sucesivos. Por lo tanto, para poder interpretar correctamente el hecho ha de ser puesto en relación con otros y estructurarlo en una cadena causal, de tal forma que su contextualización a la hora de la presentación de los acontecimientos tenga clara su exposición en toda su magnitud, es decir, una explicación cabal y global, sin ceñirse exclusivamente al acontecimiento. En esta fase, el periodista requerirá el acceso a los servicios de información y documentación — en este caso documentación escrita y audiovisual— para así poder hacerse una idea general de lo que va a comunicar. El se convierte, como emisor, en un codificador del suceso que desea transmitir - siempre y cuando no exista ninguna intencionalidad externa—, al cual le dará el tratamiento que estime oportuno.

\subsection{Noticiabilidad}

Una vez conocida la información en toda su complejidad, hay que valorar si ésta es susceptible de ser estructurada en un lenguaje periodístico para ser emitida posteriormente. Existen muchos y diferentes criterios a la hora de valorar qué noticias deben emitirse en un informativo diario de televisión de una cadena pública o privada para decidir si el acontecimiento que se está analizando es un hecho noticiable — susceptible de acabar siendo noticia emitida - o no.

Uno de estos factores es, entre otros, la importancia de la repercusión del acontecimiento. Existen noticias de repercusión internacional que son de obligada mención, como las resoluciones de la ONU o la OTAN. Otro factor muy importante a la hora de determinar si un hecho es noticiable es la cercanía (3) ya que siempre se tiende a recibir mejor aquella información en la que el televidente está relacionado de una forma directa con aquello que se relata.

Otros criterios — que no por reseñarlos después se deben considerar de menor importancia o de escaso interés - son, cuando existe una lucha feroz por la audiencia, los relacionados con el publico; es decir, lo que demanda la audiencia y aquellos que toman como punto de referencia a la competencia. Cualquiera de las televisiones que tenga en exclusiva un acontecimiento, aunque su noticiabilidad sea más que dudosa, lo emitirá señalando claramente su carácter exclusivo.

Scire. $7: 1$ (en.-jun. 2001) 153-162. 
Estos criterios responden a los criterios "comerciales" implícitos de la noticia que tanto el editor de un telediario como el periodista tienen muy en cuenta a la hora de decidir si dicha información va a ser tratada y emitida.

Todos estos factores originan la unanimidad que encontramos entre los diferentes medios de comunicación de la misma o diferente naturaleza. Es decir, entre las propias cadenas de televisión, o entre éstas y las emisoras de radio o los medios impresos, ya sean de periodicidad diaria o semanal.

\subsection{Selección o rechazo}

Una vez que se ha revisado la noticia, el grupo de periodistas estudiará si el fenómeno de noticiabilidad es lo suficientemente importante, en relación con los aspectos mencionados anteriormente. En la práctica se señala que en cuanto a los criterios de selección influye tanto lo efectista que sea una noticia como la calidad de las imágenes, que junto con el grado de iconicidad repercutirá en el valor documental posterior.

Un paso posterior a la decisión del periodista de que la noticia es válida para ser emitida es pasar el "filtro", nunca reconocido directamente, de los intereses ideológicos del canal, que van íntimamente ligados a las exigencias del público.

También hay que tener en cuenta la duración limitada de estos programas de información — que cada vez se alargan más en el tiempo de la programación (4) - y la duración, también corta, de las noticias dentro del programa informativo, así como la necesidad de aportar más tiempo a una serie de noticias — - en algunos casos repetirlas- que la dirección de la cadena determina que deben tener mayor duración que el resto de informaciones. En suma, este aspecto repercute en el nivel informativo de todo el conjunto de noticias emitidas en un telediario y en la aportación documental que se efectúe. Obliga, por un lado, a dar como noticias hechos que no tienen apenas relevancia informativa y a completar dichas informaciones con planos "de recurso" con el objetivo de ajustarse al tiempo estipulado. Por el contrario, desde el punto de vista documental, se observa como en ocasiones se ven obligados a recortar noticias que sí son de interés informativo pero cuyo tratamiento temporal limitado hace que se vea menguada su contextualización y complementación.

Otra realidad es que, a veces, los editores de estas emisiones excluyen noticias por el simple hecho de que la sección en la que se incluyen está suficientemente cargada de reseñas. Es decir, se intenta llevar a cabo y mantener un equilibrio entre la cantidad de informaciones y sus secciones. Como ya se ha aludido, todas las cadenas de televisión miran de "reojo" a la competencia para ver qué están emitiendo y, si fuera necesario, modificar la escaleta e introducir esas nuevas noticias que la competencia está ofreciendo y que "nosotros" aún no tenemos disponibles 
o no han sido preparadas en montaje. Esto origina la redundancia y coincidencia entre los contenidos que emiten las cadenas de televisión en sus diarios y que repercute en las tareas de análisis y tratamiento que se realizan en los centros de documentación de estas empresas informativas. Un punto de partida sería establecer y definir la política de selección y objetivos que se persiguen así como el expurgo que cada cierto tiempo habrá qué realizar. Esta coincidencia temática es característica común, en un alto porcentaje, en todos los medios de comunicación, debido fundamentalmente a la dependencia de éstos de las mismas fuentes de información y, en concreto, de las agencias de noticias. Por otro lado, ocasiona que en algunas televisiones se conserven todos los diarios hablados, pero que el análisis no se realice completo de todos y cada uno de los emitidos sino que se centren exclusivamente en las noticias. De esta forma, tratan de forma exclusiva la información independientemente del diario en el que aparecen. Así, nos podemos encontrar con boletines informativos que están almacenados en los centros de documentación y de ellos sólo se ha sometido a tratamiento las noticias de aquellos en los que el material se ha presentado de la forma más completa.

Por lo tanto, y una vez señalados los criterios de noticiabilidad y selección, se observa que existen consideraciones que están por encima de otros aspectos como son la primicia o exclusividad, longitud de la noticia, desarrollo futuro, equilibro del formato del programa, redundancia, etc.

\subsection{Construcción discursiva o puesta en forma de la noticia}

Una vez interpretado el hecho, éste es convertido en un discurso informativo. Es decir, se articulan imágenes, sonidos y textos (voz en off ) en un espacio y tiempo delimitado. Todo ello mediante la captación de imágenes o rodaje, el montaje o edición y la postproducción con enriquecimiento visual (grafismo) o sonoro (ambientación musical).

\subsection{Compaginación o formato}

Esta etapa es considera por Barroso García (Barroso, 1992) como la última fase del proceso productivo. La noticia volverá nuevamente a la redacción para ser analizada una vez montada, y determinar si es de calidad o, por el contrario, mejorable. En este último caso, deberá volver a montarse y editarse o, en último extremo, - si los defectos visuales o sonoros son suficientemente graves- optar por descartar la noticia de la escaleta. En esta fase la noticia deja de ser un discurso autónomo para convertirse en segmento o microdiscurso de otro superior -el propio noticiario-, que condicionará una recontextualización. Los responsables de estas decisiones fueron también los de la fase precedente (selección o rechazo) (5).

Barroso García nos presenta otra forma de estructurar la producción ya que el trabajo a realizar será el mismo en cada uno de los procesos señalados. En el

Scire. $7: 1$ (en.-jun. 2001) 153-162. 
proceso de producción de la noticia hay que valorar la forma de presentación de la información. Se analizan los códigos y los diferentes elementos expresivos atendiendo a la intencionalidad comunicadora de la empresa. No sólo se persigue que dicha información sea comprensible, sino que además impacte a los usuarios por su calidad estética, interés y atractivo. Para ello se habrán de tener en cuenta elementos formales como el encuadre, la iluminación, los movimientos de cámara, el ritmo del montaje o la estructura organizativa funcional de la información; elementos que, igualmente, se consideran a la hora de analizar cualquier imagen en movimiento. A este respecto hay que señalar que no existe una clara unificación de criterios de realización de estos productos. Muchas veces incluso se emplean sin ninguna intencionalidad.

A tenor de lo que se acaba de comentar, surge el tema de la improvisación de la que siempre se acusa a las televisiones mediterráneas. Ahora bien, este hecho es una realidad, pero, más que un aspecto negativo del trabajo, surge de la misma naturaleza del trabajo informativo, pues es muy complicado hacer una planificación y previsión de hechos que aún están por acontecer.

\section{Fases del proceso de la información televisiva de actualidad}

En el proceso o evolución que sigue cualquier información antes de ser emitida por una cadena de televisión, el departamento de documentación cobra especial relevancia e importancia en momentos concretos. Esta implicación se da fundamentalmente en la codificación de la noticia por parte del emisor, durante el tratamiento que ésta puede sufrir por parte de la agencia de noticias y, finalmente, en el propio medio de comunicación.

Las fuentes de información son varias y complejas, aunque se debe destacar el material que llega de las agencias de información nacionales e internacionales, normalmente por teletipo. La principal agencia de noticias nacional es la agencia EFE, la cual envía de manera constante aquella información que se han producido así como el aviso de acontecimientos (comparecencias, ruedas de prensa, etc.) que van a ocurrir a lo largo del día. Esta agencia adelanta noticias a la empresa audiovisual, que valorará la importancia de dicha información y el potencial de emisión de la misma de acuerdo con los factores impuestos por la empresa para la emisión. Sobre ese material que llega se realiza una selección para determinar qué información es susceptible de ser convertida en noticia en el informativo. Dicha selección la realizan a partir de los teletipos que llegan el jefe de sección y los profesionales de cada unas de las secciones en las que se encuentra dividida temáticamente. El responsable último de esta actividad será el jefe de sección.

A partir de este momento se profundiza en cada uno de los sucesos, ya que en muchos casos la información aportada por los teletipos solo ayuda a determinar el valor informativo potencial de dicho acontecimiento, pero exige un desa- 
rrollo posterior. En este caso, el personal de la sección intentará localizar a los personajes u otras fuentes que conforman dicha información para ampliar los datos sobre el evento, suceso o acontecimiento.

Posteriormente, tiene lugar una reunión por parte de los responsables de las áreas informativas en la cual se decide la información a emitir y la forma de tratarla. A primera hora de la mañana o de la tarde, dependido del diario para el cual se esté trabajando, los responsables de las diferentes áreas informativas de la empresa especifican los temas sobre los que se va a trabajar atendiendo a un tiempo inicial ideal con el que cuenta cada una. Tiempo que será modificado a tenor de criterios de noticiabilidad, cuestiones de programación y conforme a la realidad social de dicho momento. Determinado el acontecimiento que se convertirá en noticia hay que indicar la ubicación de la misma dentro del programa informativo atendiendo a los factores señalados previamente, por los cuales se rige la empresa. Esto provoca que en ocasiones encontremos noticias que no van en su sección correspondiente, sino que, de acuerdo con las circunstancias impuestas precisamente por esa noticiabilidad y repercusión, se sitúan en la cabecera del diario.

Una vez señalada la ubicación, se determina el tratamiento que se va a dar a esa información, su extensión y especialmente la duración en segundos que tendrá el equipo de reporteros para ofrecer dicho acontecimiento. La sección responsable de cubrirlo valorará la necesidad de enviar un equipo para la gestión de la noticia. En el caso de informaciones internacionales, las imágenes con las que se cuenta son aquéllas que proceden de las agencias internacionales de noticias o corresponsalías extranjeras. No obstante, para completar y contextualizar más el mensaje que se quiere emitir, con frecuencia la empresa informativa envía equipos para conocer la reacciones de personalidades nacionales. Dependiendo de la empresa, el equipo asignado será mayor o menor en número. Irá el reportero encargado de realizar la información junto con un cámara acompañado, en ocasiones, por un técnico de sonido.

No obstante, antes de que el equipo se ponga en marcha hay que evaluar diferentes aspectos. Previamente a la grabación de las imágenes y al envío del equipo de reporteros, se tiene que verificar la información con la que se cuenta. Se debe haber realizado una primera revisión de la información antes de que el personal de las secciones se ponga en contacto con la fuente de información para conocer más datos. Sin embargo, la información ofrecida por las empresas audiovisuales debe ser nuevamente verificada y contrastada. Aquí entra en juego el servicio de documentación —especialmente la unidad de documentación escrita—, a través de la cual se facilitan los datos aportados por las fuentes y por el personal encargado de la grabación de las imágenes. Esos datos pueden ser de cualquier naturaleza, tanto onomástica como geográfica o temática. Se buscarán personajes involucrados con la información, explicando la relación que puedan tener con la misma así como con

Scire. $7: 1$ (en.-jun. 2001) 153-162. 
algunas de las instituciones que hayan sido aludidas. Las posibilidades que ofrece el servicio de documentación escrita para la verificación de datos puede llegar a ser infinita. En esta labor también podrá intervenir el servicio de documentación audiovisual en casos muy concretos. Esta unidad podrá aportar aquellos datos o información necesaria, a través de imágenes o declaraciones concretas, para ofrecer y profundizar en la exactitud del material con el que se cuenta hasta este momento de cara al posterior montaje y preparación de la información. Seguidamente se realiza el plan de rodaje de las imágenes así como el guión que acompañará a la presentación de la información. En esta pequeña escaleta se determinará el plano y duración de las secuencias, que podrá modificarse si fuese necesario. La incorporación de nuevas noticias a lo largo de la jornada de trabajo provoca el reajuste en la parrilla de emisión hasta tal punto que puede ocurrir que algunas de las noticias que ya están montadas y preparadas queden fuera de la programación al haberse quedado sin tiempo en el programa informativo.En la preparación de la redacción de la noticia no sólo hay que conocer la información que se va a presentar, sino también aquel material relacionado con los antecedentes y personajes que han tenido anteriormente relación con la información. La información no se concibe como un hecho aislado, sino de forma interrelacionada con otras sucedidas en el tiempo y, a su vez, se convertirá en antecedente para noticias futuras. La contextualización de la información la aporta en algunas ocasiones el propio redactor junto con la consulta al servicio de documentación, lo cual ha de ser indicado en la locución de la noticia, si se considera oportuno por parte del personal de la empresa audiovisual.

Una vez que se sabe exactamente el plan de rodaje y se tiene información para la puesta en marcha de la noticia y especialmente para su contextualizacion por parte del periodista, se envía el equipo de periodistas a cubrir el acontecimiento. Cuando se conoce con precisión cómo se quiere montar la pieza audiovisual se utilizarán de forma específica los servicios documentales, principalmente las unidades de documentación audiovisual. Se interrogará a la base de datos solicitando todo aquel material que es necesario, tanto para ofrecer imágenes de acontecimientos relacionados con la noticia, como acontecimientos anteriores o recurso de personajes cuando el centro no cuenta con imágenes actuales. Cuando resulte necesario, se utilizarán los servicios de la unidad de documentación sonora para incorporar un corte de voz o un corte musical como fondo de la pieza audiovisual. Al mismo tiempo, se confeccionarán todos los efectos oportunos para la inclusión posterior en el producto audiovisual informativo. La rotulación será una de las últimas tareas en la "confección" audiovisual informativa. Todos estos aspectos de postproducción son importantes para la comprensión de la información presentada en el producto. La inclusión de mapas o gráficos indi- 
cadores de información deben ser consultada y revisada en el servicio de documentación de la empresa.

Previamente al montaje final de la pieza informativa hay que visionar el material grabado por los reporteros a pie de calle, así como aquel material de archivo que se ha recuperado. Hay que revisar con especial atención el material grabado para el acontecimiento. De todo ese conjunto de imágenes se extraerán aquellas secuencias que mejor representen el desarrollo de la acción que se quiere mostrar a los usuarios. En los programas informativos, una vez que se conoce el tiempo dedicado a dicha pieza audiovisual, se prepara el texto que acompañará a las imágenes. Es decir, lo primero en confeccionarse es la voz en off atendiendo al tiempo estimado para la noticia. Con posterioridad se montarán las imágenes atendiendo al ritmo y a los cortes que ofrezca la locución, incluyendo las declaraciones, si fuera oportuno, en aquel momento en que el montador así lo haya indicado. Para montar la pieza — normalmente de apenas dos minutos- habrán de tenerse adecuados conocimientos del medio y de la forma de presentación de este tipo de productos, prestando especial sensibilidad al ritmo y a las posibilidades de atención y comprensión del público en general; que es, en definitiva, el principal usuario y receptor de este tipo de acontecimientos. Una vez que el material audiovisual esté terminado para la emisión se preparará la locución que el periodista encargado de la conducción del programa informativo realizará como introducción o sumario. Dicha información debe servir para ofrecer un avance sobre el contenido de la propia noticia, aportando aquellos datos que se desean destaca. Posteriormente, el editor, o en su defecto del jefe de sección, visionará y analizará la información para ver si dicho producto tiene la suficiente calidad y valía para que la empresa emita dicha información. Dicha valoración habrá de realizarse atendiendo a política de la empresa y al conjunto armónico del informativo, ya que no sólo tiene que estar inmersa dentro del conjunto de contenidos, sino que también habrá de adjuntarse y componerse en una pieza mayor — que es la sección-y dentro de un programa completo — que es el informativo.

\section{Conclusiones}

Es indudable la importancia del servicio de documentación en cualquier empresa audiovisual especialmente durante la creación de los diferentes productos. No obstante, hay que señalar y dejar claro que cualquier empresa televisiva o cualquier otro medio de comunicación podrá funcionar y realizar su labor diaria sin que exista dicha unidad de documentación. Sin embargo, su importancia resulta evidente en ciertas informaciones como los bosquejos biográficos, montajes de archivos, retrospectivas, etc. Más en general, permiten ofrecer una información de calidad y, sobre todo, veraz, aportando criterios de credibilidad a la información ofrecida por la empresa televisiva y ayudando a evitar errores. Por último, facili-

Scire. $7: 1$ (en.-jun. 2001) 153-162. 
tan materiales de trabajo — sean fragmentos de información sobre personas, lugares y temas, así como productos completos y terminados- contribuyendo a economizar medios sin menoscabo de la calidad. Estos servicios no deben contar sólo con la conservación, tratamiento y explotación de documentación audiovisual importante activo de la empresa televisiva-, sino que además deberán estar interrelacionados con otros departamentos o unidades que controlen otro tipo de información no audiovisual. Por ello, en la mayor parte de los centros o unidades de información y documentación de estas empresas existen unidades diferentes dedicadas a la documentación audiovisual, escrita, sonora y fotográfica.

Queremos señalar en último lugar la necesidad de realizar mayores esfuerzos para dotar de un mayor y mejor número de profesionales a estas unidades de documentación, ya que en la actualidad los medios se enfrentan a gran cantidad de trabajo con un personal escaso que, ademas, no siempre cuenta con los conocimientos necesarios para la práctica diaria de su trabajo (6).

\section{Notas}

(1) Algunos autores han reducido el proceso a tres fases — recolección, selección y presentación - con lo que estamos plenamente de acuerdo. Únicamente se ha subdividido algo más para evidenciar la intervención dentro del periodismo televisivo de profesionales con especialidades distintas, pero que trabajan de forma homogénea gracias a los valores profesionales que comparten con independencia de que trabajen con materiales escritos o no.

(2) No existe ninguna fuente de información escrita publicada que nos señale cuál es el número de teletipos o notas de prensa que llegan diariamente a los servicios informativos de las diferentes televisiones en España.

(3) Un hecho noticiable podría ser un accidente de tráfico en el que murieran cinco jóvenes en una carretera comarcal de Toledo. Sin embargo, estas mismas muertes no son noticia si se han producido fuera de nuestras fronteras.

(4) En otro extremo, esto repercute en el producto final que hace que, en ocasiones, tengan que ofrecerse como noticias hechos de poca relevancia informativa o que se tenga que acortar la presentación y exposición de noticias importantes ante esa limitación temporal.

(5) La decisión final en la selección de cualquier noticia está en manos de la figura del editor. Debemos indicar igualmente que existen momentos en que esta figura no es un factor decisivo sino que las pautas pueden venir determinadas por directivos de la empresa televisiva.

(6) Este trabajo ha sido financiado por la Junta de Extremadura - Consejería de Educación, Ciencia y Tecnología y el Fondo Social Europeo, como parte del proyecto de investigación IPR99A044.

\section{Referencias}

Barroso García, J. (1992). Proceso de la información de actualidad en televisión. Madrid : IORTV, 1992. 
Introducción a la documentación informativa y periodística (1999). Sevilla : MAD, 1999. Manual de documentació audiovisual en ràdio i televisió (1999). Valencia : Universitat, 1999. Manual de documentación informativa (2000). Madrid : Cátedra, 2000.

Manual de documentación periodística (1995). Madrid : Síntesis, 1995. 